\title{
Reflexões sobre o aconselhamento em HIV/AIDS em uma perspectiva freireana
}

\author{
Reflections about the use of counseling in HIV/AIDS under the perspective of Freire \\ Reflexiones sobre el uso de consejos en VIH/SIDA bajo la perspectiva de Freire
}

\author{
Karla Corrêa Lima Miranda', Maria Grasiela Teixeira Barroso", \\ Lucilane Maria Sales da Silva', Maria Rocineide Ferreira da Silva' \\ 'Universidade Estadual do Ceará. Departamento de Enfermagem, Programa de Pós-Graduação em Cuidados Clínicos. Fortaleza, CE \\ "Universidade Federal do Ceará. Departamento de Enfermagem. Fortaleza, CE
}

\section{RESUMO}

Nesta reflexão nos propomos a analisar o aconselhamento a partir da visão da pedagogia freireana visualizando-o de forma mais ampla, como uma atividade de educação, um "ato de intervenção" para a autonomia do sujeito. O aconselhamento é uma atividade desenvolvida por um profissional de saúde, devidamente treinado, e destina-se a Quem deseja ou tem indicação de realizar a sorologia anti-HIV. No âmbito da epidemia de HIV/AIDS, o processo de aconselhamento contém três componentes: o apoio emocional ao cliente; apoio educativo; e avaliação de riscos, Que propicia a reflexão sobre valores, atitudes e condutas. Dessa forma, evitarão ser ele convertido em um "bate-papo" descomprometido e conduzido conforme a vontade do aconselhador.

Descritores: Aconselhamento; Infecções por HIV; AIDS; Educação em saúde.

\section{ABSTRACT}

This reflection intended to analyze the counselling starting from the vision of the Freire's pedagogy visualizing it in a wider way, as an education activity, an intervention act for the subject's autonomy. The counselling is an activity developed by a Health professional, properly, and it is destined to who has indication of accomplishing the anti-HIV. In the ambit of the epidemic of HIV/AIDS, the counselling contains three components: the emotional support to the customer; educational support; and evaluation of risks, that propitiates the reflection on values, attitudes and conducts. In that way, they will avoid to be he turned into a no obligation "chat" and led according to the counselor's will.

Descriptors: Counseling; HIV infections; AIDS; Health education.

\section{RESUMEN}

En esta reflexión nos proponemos analizar el consejo a partir de la visión de la pedagogía freireana visualizándolo de forma más amplia, como una actividad de educación, un "acto de intervención" para la autonomía del sujeto. El consejo es una actividad desarrollada por un profesional de salud, debidamente entrenado, y se destina a Quien lo desea o está indicado para realizar la serología anti-VIH. En el ámbito de la epidemia de VIH/SIDA, el proceso de consejo contiene tres componentes: el apoyo emocional al cliente; el apoyo educativo; y la evaluación de riesgos, Que propicia la reflexión sobre valores, actitudes y conductas. Así, evitarán Que se convierta en una charla sin compromiso y dirigido según la voluntad del aconsejador.

Descriptores: Aconsejar, Infecciones por VIH; SIDA; Educacíon en salud. 


\section{INTRODUÇÃO}

Durante o início da década de 80 do século XX a população mundial presenciou o surgimento, nos Estados Unidos, da Síndrome da Imunodeficiência Adquirida (AIDS), causada por um vírus, denominado posteriormente com a sigla de HIV, tendo este tomado proporções mundiais com casos registrados em todos os países do mundo, e Que apesar dos avanços relacionados ao conhecimento do vírus, do desenvolvimento da síndrome e da terapia medicamentosa Que possibilitou uma maior expectativa de vida para as pessoas contaminadas, as possibilidades de cura ainda são remotas. Estas afirmativas apontam para a necessidade de produção de pesquisas que possam contribuir direta ou indiretamente para o controle da epidemia, para reflexões sobre o processo de trabalho em HIV/AIDS e, principalmente, para o aperfeiçoamento da assistência dirigida às pessoas atingidas.

No Brasil, casos da infecção pelo HIV foram registrados logo no início da década de 80 , mas a política de assistência aos portadores do HIV/AIDS só foi estruturada 10 anos depois, no início da década de 90, e tinha como fundamento a obtenção da melhoria na Qualidade de vida dos pacientes e racionalização dos recursos humanos e financeiros ${ }^{(1)}$.

Entretanto, diante dos primeiros casos de HIV/AIDS no Brasil, o Ministério da Saúde sentiu a necessidade de sensibilizar profissionais de saúde para trabalhar com situações apresentadas pela infecção ou pela doença. O aconselhamento foi à estratégia encontrada nos serviços em DST/AIDS para profissionais de saúde atenderem a demanda Que procurava orientação e apoio frente à realização da sorologia anti-HIV. Ainda com a epidemia em ascensão, houve a necessidade de ampliar a demanda de profissionais de saúde em unidades ambulatoriais e laboratórios de instituições públicas e hospitalares para atender pacientes com HIV/AIDS na prática do aconselhamento( ${ }^{(1)}$.

O aconselhamento é uma atividade desenvolvida por um profissional de saúde, devidamente treinado, e destina-se a Quem deseja ou tem indicação de realizar a sorologia anti-HIV. No âmbito da epidemia de HIV/AIDS, o processo de aconselhamento contém três componentes: o apoio emocional ao cliente; apoio educativo; e avaliação de riscos, Que propicia a reflexão sobre valores, atitudes e condutas incluindo o planejamento de estratégias de redução de riscos. O aconselhamento pauta-se em uma relação de confiança entre profissional e cliente e se estabelece por meio da atitude de escuta e de uma comunicação clara e objetiva. Portanto, se realizado conforme está previsto, o aconselhamento é uma referência importante para o trabalho com HIV/AIDS, na medida em Que propicia uma relação de confiança entre profissional e usuário, e torna o indivíduo sujeito no processo de prevenção e no cuidado de $\mathrm{si}^{(1)}$.

Com o reordenamento do perfil epidemiológico da pandemia, houve a necessidade de se ampliar a oferta de testagem sorológica voluntária, confidencial, assegurando ao usuário o aconselhamento pré e pós-teste. A partir de 1988, foram implantados os centros de orientação e apoio sorológico, hoje denominados centro de testagem e aconselhamento (CTA), Que passaram a ser a principal referência em aconselhamento.

Atualmente os profissionais de saúde de centro de testagem e aconselhamento (CTA), serviço de assistência especializada (SAE),
Que trabalham com DST e algumas instituições públicas hospitalares Que atendem pacientes com HIV/AIDS, foram treinados na prática do aconselhamento com o objetivo de atender de forma adequada os usuários Que recorrem a estes serviços, procurando informações e a testagem sorológica para o HIV em todo o território nacional brasileiro. Em cada serviço de saúde, a equipe responsável pelo aconselhamento pode variar, de acordo com os profissionais lotados na unidade.

Com o aumento do número de mulheres com HIV/AIDS, este serviço está em expansão, sendo incluído entre os Que realizam pré-natal, para dar suporte emocional e cognitivo a Quantas gestantes desejarem submeter-se à sorologia anti-HIV.

\section{REFLETINDO SOBRE A PRÁTICA DO ACONSELHAMENTO}

Com a finalidade de avaliar as ações de aconselhamento desenvolvidas em serviços do Sistema único de Saúde onde este acontece, estudo identificou, por meio de um levantamento, Que os profissionais muitas vezes se concentram em um roteiro previamente elaborado, dificultando a relação, a reflexão e o diálogo com o seu cliente ${ }^{(2)}$.

Outros estudos com o objetivo de analisar as causas de nãoadesão e dificuldades enfrentadas pelos usuários de um CTA na realização da sorologia anti-HIV. Conforme indicam os principais dados encontrados pelas pesquisadoras, a grande dificuldade é o não - retorno dos usuários ao serviço para a realização da segunda sorologia Quando o primeiro resultado foi negativo. Este fato advém da ansiedade e medo em face do diagnóstico sorológico. Outro dado importante decorrente do estudo foi à dificuldade em criar vínculo entre profissional e usuário, a Qual, de acordo com as pesQuisadoras, justifica a não - procura para uma segunda testagem, como recomenda o Ministério da Saúde, independente de ser a primeira sorologia negativa ${ }^{(3)}$.

Para se trabalhar na prevenção do HIV/AIDS algumas teorias em Educação em Saúde poderiam ser utilizadas; entre elas, a abordagem humanista, comportamental, político-social. Consoante, concluem as autoras, as abordagens educativas têm falhado por não contemplar o aspecto afetivo na construção do conhecimento, pois os modelos estão orientados fundamentalmente no aspecto cognitivo. Não basta haver conhecimento para existir a sensibilização a uma tomada de decisão. Faz-se necessário uma metodologia educativa Que estimule o educando a uma reflexão crítica sobre a sua realidade e a construção de seu discurso para a autonomia ${ }^{(4)}$.

Vários estudos epidemiológicos, realizados nos Estados Unidos e Inglaterra, duvidam da eficácia do aconselhamento, porQuanto levam em conta apenas à utilização do preservativo e a adesão às consultas subseQüentes.Em contrapartida, evidenciou-se também a importância e eficácia do aconselhamento como um dispositivo preventivo. Como observado em seus estudos, os grupos Que tiveram acesso ao aconselhamento em 37 clínicas nos Estados Unidos da América, com sete sessões de aconselhamento, informaram menos relações sexuais desprotegidas e uso mais constante de preservativo no período de um ano ${ }^{(5-8)}$.

Em ensaio clínico randomizado mostrando a eficácia do aconselhamento na redução das DSTs entre indivíduos heterossexuais HIV negativos. Segundo evidenciado por este estudo, 
os sujeitos submetidos a dois aconselhamentos utilizavam o preservativo em sua totalidade e apresentavam 30\% menos incidência de DST Que o grupo Que não tinha vivenciado o aconselhamento ${ }^{(9)}$.

Consoante percebemos, os estudos em aconselhamento estão direcionados a verificar Quantitativamente a eficácia do aconselhamento, motivos, dificuldades do usuário ou o perfil da clientela Que utiliza os serviços de testagem. Entretanto, estes estudos chamam de eficácia a utilização de preservativos, a diminuição de incidência das DSTs, ou adesão e comparecimento às consultas previamente agendadas. Estes são dados importantes e podem contribuir para diminuição de enfermidades. Tais estudos, porém, partem do pressuposto de Que o homem é um ser influenciado pelo meio. Por isso, ao ser estimulado e incentivado com palavras positivas, pode apresentar mudança de comportamento. Esta é a característica da teoria comportamental, segundo a Qual o homem é uma "tábula rasa", Que podemos adaptar e programar para viver melhor.

\section{A VISÃO DO ACONSELHAMENTO NA PRESPECTIVA FREIREANA}

Esta visão de ser humano está muito distante daQuela postulada pelo aconselhamento como uma atividade educativa na perspectiva freireana, pois o homem pensado por ele é um ser existencial, está no mundo e com o mundo. Não se pode estimular este homem à mudança sem entender sua existência, sua visão e interpretação deste mundo. As mudanças de atitudes, como uso do preservativo, diminuição das DSTs, seriam conseQüência do entendimento e compreensão de sua realidade e ações, não a única finalidade.

Não nos foi possível identificar estudos Que trabalhem o aconselhamento na perspectiva educacional, no foco deste estudo, para além da informação, Que não esteja centrado no pragmatismo e funcionalismo.

Sobre a dificuldade da passagem do conhecimento para a ação em relação ao processo educativo, devemos refletir e pensarmos em estratégias de intervenção levando em conta as singularidades das populações a Que se destinam estas atividades ${ }^{(10)}$.

Visualizamos, então, o aconselhamento de forma mais ampla, como uma atividade de educação, um "ato de intervenção" para a autonomia do sujeito. $\mathrm{O}$ aconselhamento, nesta perspectiva, é um ato de conhecimento, uma situação gnosiológica; é comunicação, diálogo, interação. Logo, ser humano é sujeito de sua educação, não podendo ser objeto dela, por isso, nessa concepção, ninguém educa ninguém. A educação é troca, são homens e mulheres educando e sendo educados mutuamente. Ela deve ser desinibidora, libertadora, uma força de mudança, desenvolvendo o ímpeto de criar. É, pois, necessário dar liberdade aos educandos para decidirem e fazerem suas escolhas Por isso ela é política porQue é um projeto a ser construído, imbuído de esperança e luta. Portanto, o aconselhador, como um educador na perspectiva freireana, deve acreditar no aconselhamento para a educação e na capacidade de intervenção no mundo do aconselhando ${ }^{(1-16)}$.

Neste contexto, Freire já nos fala de uma educação Que está para além da informação, da reprodução, pois está para a transformação. Desta forma, a obra de Freire discute várias Questões, entre estas as fomentadas no relatório para a UNESCO da Comissão Internacional sobre a Educação para o Século XXI. Neste documento, são discutidos os Quatro pilares da educação, Quais sejam: aprender a aprender, aprender a fazer, aprender a conviver e aprender a $\operatorname{ser}^{(17)}$.

Essa observação se objetiva em princípios Que deverão nortear a satisfação das necessidades do cidadão, Quais sejam: a estética da sensibilidade onde ao se associar o aprender ao fazer estimulasse o potencial criativo, a afetividade, o respeito a diversidade tão necessários em tempos atuais fortalecendo a política da igualdade, espaço de fortalecimento do aprender a conviver com reconhecimento dos direitos humanos Que se assumem eneuanto expressão de participação e solidariedade e então, a ética da identidade como reflexo do aprender a ser onde a partir do reconhecimento da identidade própria e do outro teria como resultado final a autonomia do sujeito ${ }^{(18)}$.

As opiniões dos autores sobre este relatório se dividem. Alguns autores defendem Que as idéias freireanas superam o relatório, o Qual se limita ao preparo do educando para o mundo do trabalho. Eneuanto outros se posicionam a favor do relatário pois traz a necessidade de uma educação responsável por criar pessoas éticas e solidárias ${ }^{(19-20)}$.

Podemos observar, portanto, Que Paulo Freire, há várias décadas, se preocupava com estas Questões, como conhecer, ser mais, interagir pelo diálogo. Tudo isso Freire afirma sem pragmatismo, ultrapassando a capacitação para o mercado ou para a economia. Em suas últimas publicações, Que datam de 1990, ele nos falava de uma educação solidária, planetária e ética, impregnada de amor e esperança.

Com base em Freire, acreditamos que o aconselhamento realizado na perspectiva dialogal, reflexiva e crítica poderá ser efetivo como instrumento para a formação de uma consciência crítica e, assim, possibilitará compreender a realidade do ser humano para sua autonomia.

Paulo Freire dialoga com vários pensadores e fundamenta sua visão de homem e mundo, sua relação e a capacidade do sujeito de fazer suas escolhas e ser dono do seu destino. Interpreta as diversas situações humanas apoiado na corrente filosófica do Existencialismo. Utiliza também alguns conceitos, como o de liberdade, entre outros descritos em suas obras. A liberdade, para esse autor, é um dos conceitos de maior destaque em toda a sua obra. Ser livre para ele é o exercício do sujeito na construção da sua palavra, é pronunciar o seu discurso para ser protagonista do seu destino.

No sentido de trazer nossa colaboração, proporcionando um aconselhamento mais reflexivo, centrado na demanda pessoal de cada aconselhando, não priorizando apenas a cognição, como também minimizar o sofrimento percebido pelo aconselhador Quando ele se vê como centro do aconselhamento, é Que propomos um aconselhamento baseado nos pressupostos freireanos. Esta idéia possibilita um aconselhamento como um momento educativo, pois o aconselhando traz para o mesmo sua realidade vivida; a partir dessa, o aconselhador partilha com este sujeito a construção de Questões a serem exploradas e discutidas. Por meio dessa construção elaborada entre aconselhador e aconselhando, haverá uma desconstrução do Que foi abordado e Que não esteja coerente, para posteriormente se reconstruir Questões e uma nova realidade. Esta proposta teórica possibilitará ao aconselhador a 
instrumentalização fundamentada em uma metodologia em aconselhamento apoiada em Freire, conforme a seQüência seguinte:

- A construção da realidade vivida- neste momento acontece a identificação da realidade significativa do aconselhando. È o momento de construção, Quando o aconselhador, mediante diálogo, despertando a curiosidade do aconselhado, explora Questões relacionadas com a vida cotidiana deste, sua visão de mundo, sua percepção em relação à AIDS, sua vulnerabilidade e sua história. A partir deste diálogo, o aconselhador encoraja o sujeito a fazer sua pergunta, possibilitando discutir, desmistificar e trabalhar exemplos práticos de situações existenciais vividas pelo sujeito.

- A desconstrução da realidade- este é o momento da codificação e decodificação das Questões trazidas pelo aconselhando, partindo do contexto vivido por ele e dos exemplos práticos elaborados pelo aconselhador. À medida Que se dialoga com os sujeitos, evidenciase para um ou outro o ponto menos claro, mais ingênuo, problematizando-o. As perguntas Que podemos fazer seriam: Por Quê? Como? Será assim? Na desconstrução, destacam-se as convergêncais e as divergências entre os discursos. Representa, então, a análise de uma situação existencial concreta e sua decomposição, isto é, a passagem do abstrato ao concreto, da parte ao todo, para depois voltar às partes. Tudo isso para se chegar a um nível crítico de conhecimento, começando pela experiência do sujeito Quanto à sua situação em seu contexto real.

- A reconstrução e as possibilidades dos inéditos-viáveis- este momento significa a união de novos saberes com a realidade a ser apreendida. Buscam-se as possibilidades de inéditos-viáveis. Esta é uma proposta prática de superação, pelo menos em parte, dos aspectos opressores percebidos no momento dialógico, Quando o aconselhador pensa com o sujeito as alternativas de solução dos problemas apontados por ele. Juntos identificam estratégias de intervenção capazes de superar as situações geradoras de conflitos.

Em síntese, com recurso do diálogo problematizador entre aconselhador e aconselhando, propomos o fortalecimento de uma prática educativa capaz de possibilitar a descoberta da palavra do sujeito aconselhado, e Que esta atitude resulte na transformação de sua história e na construção de um mundo mais humano. Na utilização e ressignificação dos pressupostos inseridos na obra de Paulo Freire, como também Quando da releitura e atualização do método e de alguns conceitos propostos por ele, consideramos Que o sujeito traz para o aconselhamento uma realidade vivida, a Qual podemos chamar de primeira, nomeada auui de realidade construída. Após a discussão desta realidade, codificação e decodificação, o sujeito entrará em contato com uma segunda realidade, a realidade aprendida, Que nomeamos de realidade desconstruída. Posteriormente, ambos - sujeito e aconselhador após interpretação e reinterpretação das realidades, organizam juntos possibilidades de intervenção e transformação da realidade, denominada, neste passo, de reconstrução da realidade.

Para tal, urge reorganizar a prática do aconselhamento. Que o aconselhador defenda o aconselhamento como um ato também político e se engaje na construção de um projeto educativo de aconselhamento, no Qual, pelo diálogo amoroso, aconselhador e aconselhando possam construir juntos uma educação para a liberdade, denunciando as amarras e anunciando um projeto para autonomia da pessoa. O aconselhamento como ação educativa necessita sair da reprodução e partir para uma forma metodologicamente fundamentada como atividade educacional na perspectiva - como enfatizamos neste estudo - de uma educação para a transformação e autonomia da pessoa, propiciando ao aconselhador, pela curiosidade epistemológica, a passagem de uma consciência ingênua para uma consciência crítica, fomentando a leitura da realidade e a possibilidade da autonomia.

Tudo isto, no entanto, só será possível se as instituições normatizadoras do aconselhamento o entenderem na perspectiva educativa freireana, na Qual o profissional disponha de tempo e de condições suficientes para cumprir esta atividade. Faz-se necessário Que as instituições governamentais valorizem a educação para valorizar também o aconselhamento. Dessa forma, evitarão ser ele convertido em um "bate-papo" descomprometido e conduzido conforme a vontade do aconselhador.

Insistimos na idéia de Que, somente na grande luta, em comunhão com todas estas instituições e em rede, poderemos construir esse sonho possível. É fundamental pensarmos numa teoria e prática com "feições de beleza", para além da cognição, levandose em conta a ação, e o afetivo. Desta forma, podemos estar mais próximos de uma ação educativa para a liberdade e autonomia do sujeito.

\section{REFERÊNCIAS}

1. Ministério da Saúde (BR). Coordenação Nacional da DST/AIDS. Aconselhamento em DST/HIV e AIDS: diretrizes e procedimentos básicos. Brasília: Ministério da Saúde; 1999.

2. Filgueiras SL, Delantes S F. Avaliação das ações de aconselhamento. Análise de uma perspectiva de prevenção centrada na pessoa. Cad Saúde Pública 1999; 15(1): 12 1-31.

3. Santos F, Machado A. Pesquisa em AIDS, dificuldades em adesão pelos indivíduos soronegativos. Rev Bras Doenças Sex Transm 2001; 13(5): 43-5.

4. Schall VT, Struchiner M. Educação no contexto da epidemia de HIV/AIDS: teorias e tendências pedagógicas. In: Czeresnia D, Santos EM, Barbosa RHS, Monteiro S. AIDS: pesquisa social e educaçäo. Saúde e Debate 1995; 84- 105.

5. Bradson B, Peterman T. Group counselling to prevent sexually transmitted disease and hiv: a randomized controlled trial. Sex

Transm Dis 1998; 553-9.

6. Bentley ME, Spratt K, Shepherd ME, Gangakhedkar RR, Thilikavathi S, Bollinger RC, Mehendale SM. HIV testing and counselling among men attending sexually transmitted disease clinics. AIDS 1998; 12(4): 1869-77.

7. George N, Green I. Sexually transmitted disease rates before and after HIV testing. Int I Stud AIDS 1998; 9(5): 291-3.

8. Schreibman T, Friedland G. Human immunodeficiency virus infeccion prevention: strategies for clinicians. Clin Infect Dis 2003; 36(9): 1171-6.

9. Kamb MI, Fishbein M, Douglas IM. Efficacy of risk-redution counseling to prevent human immunodeficiency virus and sexually transmitted diseases: a randomized controlled trial. IAMA 2002; 280(2): 1 161-7.

10. Morondo N. La educación para la salud sobre vih/sida. In: 
Anais do Congresso Nacional sobre VIH/SIDA. 1997 jan $2-$ 7 ; Barcelona (ESP). Barcelona; 1997. p. 30-4.

11. Freire P. Educação e mudança. 19a ed. São Paulo: Paz e Terra; 1979.

12. Freire P. Conscientização: teoria e prática da libertação- uma introdução ao pensamento de Paulo Freire. $3^{\text {a }}$. ed. São Paulo: Moraes; 1980.

13. Freire P. Pedagogia da autonomia: saberes necessários à prática educativa. $2^{a}$. ed. Rio de Janeiro: Paz e Terra; 1997.

14. Freire P. Educação como prática da liberdade. 23ª. Ed. Rio de Janeiro: Paz e Terra; 1999.

15. Freire P. Pedagogia do oprimido. 29a. Ed. São Paulo: Paz e
Terra; 2000.

16. Freire P. À sombra desta mangueira. $4^{\mathrm{a}}$. ed. São Paulo: Olho D’água; 2001.

17. Delors J, organizador. Educação: um tesouro a descobrir. relatório para a unesco da comissão internacional sobre educação para o século XXI. 5a. ed. São Paulo: Cortez; 2002.

18. Ramos MN. A pedagogia das competências: autonomia ou adaptação. São Paulo: Cortez; 2002.

19. Romão JE. Avaliação dialógica: desafios e perspectivas. $3^{\mathrm{a}}$. ed. São Paulo: Cortez; 2002.

20. Brandão CR. A educação popular na escola cidadã. Petrópolis: Vozes; 2002. 